
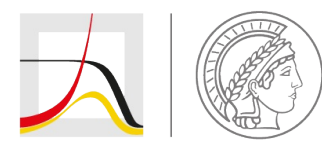

MAX PLANCK INSTITUTE

FOR DEMOGRAPHIC RESEARCH

Konrad-Zuse-Strasse 1 · D-18057 Rostock · Germany · Tel +49 (0) 3812081 - 0 · Fax +49 (0) 3812081 - $202 \cdot$ www.demogr.mpg.de

MPIDR Working Paper WP 2021-022 I November 2021

https://doi.org/10.4054/MPIDR-WP-2021-022

\title{
Cohort changes and drivers of education-specific union formation patterns in sub-Saharan Africa
}

Ben Malinga John I john@demogr.mpg.de Natalie Nitsche I nitsche@demogr.mpg.de

This working paper has been approved for release by: Mine Kühn (kuehn@demogr.mpg.de),

Deputy Head of the Laboratory of Population Health.

(c) Copyright is held by the authors.

Working papers of the Max Planck Institute for Demographic Research receive only limited review. Views or opinions expressed in working papers are attributable to the authors and do not necessarily reflect those of the Institute. 


\title{
Cohort changes and drivers of education-specific union formation patterns in sub-Saharan Africa
}

\author{
Ben Malinga John ${ }^{1,2,3}$ \& Natalie Nitsche ${ }^{1}$ \\ ${ }^{1}$ Max Planck Institute for Demographic Research, ${ }^{2}$ Stockhom University, ${ }^{3}$ Univeristy of \\ Malawi
}

\section{Acknowledgements}

We are grateful for the feedback on an earlier version of this paper we received from Elizabeth Thomson and Sunnee Billingsley of the University of Stockholm, Vissého Adjiwanou of Université du Québec à Montréal and the $\mathrm{PhD}$ reading group of the Population Health and Data Science program at Max Planck Institute for Demographic Research. Their insights helped us tremendously to refine the message of this manuscript. Nonetheless, none of them is responsible for how we decided to use their comments and suggestions.

\section{Data availability statement}

The data used in this paper are openly available at https://dhsprogram.com/data/available datasets.cfm 


\begin{abstract}
Despite education expansion, age at first marriage stalled in some sub-Saharan African (SSA) regions, a pattern whose underlying drivers remain poorly understood. We argue that a deeper investigation of birth cohort changes in education-specific ages at first marriage and how they are aligned with changes in girls' school participation can illuminate this puzzle. Using Demographic Health Survey data from 34 SSA-countries, survival analyses and decomposition techniques, we examine education-specific marital behavior and change therein for the cohorts born between 1940 and 1999. Three key findings come to the fore. First, median age among all education groups stalled or reversed over some birth cohorts in all SSA regions. Second, these education-specific stalls or reversals correspond to different stages of education expansion across SSA regions. For some regions, these occurred long before the proportion of women attaining some schooling had increased substantially. Third, behavioral rather than education group composition changes explain the largest component of cohort differences in marriage rates in these education group. We conclude that increases in secondary education would be the most likely pathway to further delays in age at first marriage in West, Central and East Africa.
\end{abstract}

Keywords: Marriage, Age at marriage, Union formation, Female education, sub-Saharan Africa, Cohort analysis 


\section{Introduction}

Marriage is one of the key markers of transition to adulthood in sub-Saharan Africa (SSA). The timing of this event predefines an individual's life course trajectory in several aspects. For example, women who marry at younger ages face a higher risk of early childbearing and are thus selected for high lifetime fertility (Westoff 1990) and pregnancy-related complications (Althabe, Moore et al. 2015, Grønvik and Fossgard Sandøy 2018). Early union formation is also linked to a higher likelihood of experiencing intimate partner violence and union dissolution (Clark and BraunerOtto 2015, Kidman 2017), both of which have adverse consequences for women's socioeconomic and health outcomes. Thus, understanding changes in marital timing over time, space, and across generations and illuminating the factors that explain such behavioral change is critical for potentially advancing women's reproductive health and social experience in this region.

Until the late 1990s, marriage was marked as early and universal in SSA. The median age at first marriage among women varied around 15-19 years for most countries (Westoff and Macro 2003, Garenne 2004). This pattern is slowly shifting, with more women postponing marriage to later ages, and in some regions (particularly in Southern Africa), more women are starting to forgo this transition (Garenne 2004, Mensch, Singh et al. 2005, Posel and Rudwick 2013, Hertrich 2017). Prior research has linked these changes to the expansion of education among girls and women (Mensch, Singh et al. 2005, Shapiro and Gebreselassie 2014, Bongaarts, Mensch et al. 2017); however, little empirical evidence exists on long term changes in the timing and quantum of marriage by level of education.

The connection between changes in marital timing and educational expansion has been theorized to operate through various pathways. For instance, via (i) the postponement of marriage until after schooling is finalized (avoidance of simultaneous school enrollment and family formation) (Lloyd and Mensch 2008, Glynn, Sunny et al. 2018, Zuilkowski, Henning et al. 2019), (ii) the acquisition of new ideas and norms that weakens traditional customs that stimulate early union formation (Caldwell 1980), (iii) the pursuit of gainful employment beyond school finalization (opportunity costs) (Becker 1973), and via (iv) the restructuring of marriage markets, particularly where assortative mating dominates (Pesando 2021).

For marriage postponement primarily driven by avoidance of simultaneous school enrollment and family formation, age at marriage should be anticipated to increase as long as female education expansion occurs through compositional change concerning educational attainment. Indeed, Bongaarts, Mensch et al. (2017) noted that the change in female education composition between 1993 and 2010 was the main driver of marital timing changes during this period in SSA. Despite changes in marital behavior within educational groups, this compositional factor was so dominant that mean age at marriage would still have increased even if marital behavior for specific education groups had remained the same (ibid.). Further, if education expansion leads to a universal delay in age at marriage, such an effect should be uniform across 
Africa. Grant (2015) termed such expectations "the demographic promise of expanded female education." (p.2).

However, such anticipations have barely materialized in some countries such as Burkina Faso, Chad, Ethiopia, Madagascar and Malawi, where girls' school participation expanded substantially without considerable marital timing delays (ICF 2015, Bongaarts, Mensch et al. 2017). Mensch, Singh et al. (2005) also observed a similar pattern, noting that in about one-third of SSA countries, the level of the observed decrease in the proportion of women married before age 18 was merely less than half of what they predicted (using a regression model) based on observed changes in educational attainment. Poor quality of education following the introduction of free primary education in the 1990s and 2000s, the change in age patterns of school enrollment, and lowered selectivity of women who attended school in recent decades are some of key hypothesized mechanisms put forward by experts to explain the stalls in age at marriage and other reproductive events in this region (Grant 2015, Bongaarts, Mensch et al. 2017). However, there is little, if any, empirical evidence to support these hypotheses largely because the very descriptive building blocks we need to test them (such as the life course data on the timing of marriage, timing of school enrollment and completion, economic activity and aspirations for it after school completion) are lacking.

Nevertheless, although detailed panel data on the occurrence and timing of family formation events, educational- and employment trajectories in SSA are not available to address such hypotheses, a systematic analysis linking long-term cohort changes in marital timing with changes in girls school participation could provide fundamental descriptive evidence needed to shed some insights into these dynamics. Yet, such analyses have to date not been undertaken. Our study closes this gap by providing two types of estimates. First, we examine aggregate union formation patterns for specific education groups during female education expansion. Precisely, we assess whether marriage rates stalled in all educational groups and how education-specific marriage rates evolved over birth cohorts to illuminate how the timing of stalls in age at marriage aligned with the stage of female education expansion. We question whether limited changes in age at marriage at the population level primarily rose from stalls or reversals in age at marriage for some or all education groups. We further examine if age at marriage stalled or reversed for the primary or secondary education group, whether such stalls occurred when the composition of women in these groups increased substantially, and at what threshold they happened. Second, we assess education-specific cohort differences in marriage rates to identify factors central to these changes. Our focus is on examining the extent and direction to which the composition of education groups (e.g. changes in the proportion of women with complete education or from rural areas- due to extension of schools to these communities) influenced marriage rates. This later analysis sheds more light on the proposition that age at marriage might have stalled due to women with some education becoming less selected as female education expanded (Grant 2015, Bongaarts, Mensch et al. 2017). 
We used data from 139 Demographic and Health Surveys (DHS) collected between 1986 and 2019 in 34 SSA countries to provide these fundamental descriptive blocks. These countries are grouped into four broader regions: West, Central, East and Southern Africa, following a standard classification in the literature (See, for example, United Nations Sustainable Development Goals Regions (United Nations 2019)). Our estimation procedure follows event history analysis techniques. First, we rely on the Kaplan Meier method to produce education-specific median age at first marriage. We then apply a discrete-time to event logit model and perform a multivariate decomposition analysis of cohort differences in marriage rates for women with primary and secondary education separately. Our findings provide evidence that shed some insights into the linkage between female education expansion and the timing of reproductive events in SSA, at least in two ways. First, we observe that median ages at first marriage among all education groups stalled or reversed in SSA regions. However, these education-specific stalls or reversals corresponded to different stages of education expansion across SSA regions. For some regions, these occurred long before the proportion of women attaining some schooling had increased substantially. These findings demonstrate that other factors than conditions assumed to have emerged due to the expansion of female education itself might have been at play in shaping these stalls. Second, we find evidence suggesting that behavioral rather than compositional changes explain the largest component of cohort differences in marriage rates for women with primary and secondary education. Thus, it appears that changes in group selectively, as female education expanded, likely played little influence in cohort differences in age at marriage in these regions.

\section{Background}

\section{Expansion of female education and marital timing changes in sub-Saharan Africa}

The rise in girls' school enrollment in SSA triggered anticipation of potential delays in the timing of first marriage and other critical life-course events in this region. The negative association between educational attainment and age at first marriage documented in the literature (Jejeebhoy 1995, Mensch, Singh et al. 2005) gave more weight to this anticipation, and Grant (2015) termed this prospect "the demographic promise of expanded female education". However, this anticipation has barely materialized in some countries. For example, in Malawi, the proportion of women aged 15-49 who attended school increased from 52.8 in 1992 to 87.9 in 2015. Those with at least secondary education rose from $4.4 \%$ to $25.8 \%$. Nonetheless, the age at which half of the women aged 20-49 first married (median age) only increased by 0.6 years during this period (ICF 2015). In Chad, the median age at first marriage nearly remained stable while the percentage of women aged 15-49 with no education dropped from 77\% in 1996 to 62\% in 2014, and those with some secondary education increased from $3.8 \%$ to $14.9 \%$. Stalls in age at first marriage are also apparent in Burkina Faso, Ethiopia, Madagascar, Mozambique and Tanzania (ICF 2015, Bongaarts, Mensch et al. 2017). Mensch, Singh et al. (2005) also observed a similar pattern, noting that in about onethird of SSA countries, the level of the observed decrease in the proportion of women married 
before age 18 was merely less than half of what they predicted (using a regression model) based on observed changes in educational attainment.

Understanding how educational attainment is associated with union formation helps explain why age at marriage could stall amidst rising girls school participation. In SSA, education attainment is tied to the postponement of marriage through at least three dominant pathways. First is the incompatibility hypothesis, which postulates that the time women spend in school is directly linked to their union formation timing due to an incompatibility of simultaneous school enrollment and family formation. School attendance in this region (especially primary and secondary education) generally means postponing marriages to later ages, while initiating family signals discontinuity of schooling (Lloyd and Mensch 2008, Glynn, Sunny et al. 2018, Zuilkowski, Henning et al. 2019). Thus, the longer women stay in school, the more marriages are delayed to later ages. Therefore, the strength of this mechanism is contingent on at least the age at school enrollment, the pace of grade progression, school completion rate, the minimum number of years required to complete a specified education level, and opportunities for girls to proceed further with education beyond the secondary level. A high completion rate would imply staying longer in school - at least for as many years as required to graduate - hence, it would negatively affect the risk of union formation.

On the other hand, if school starts at younger ages and progression through grades is rapid, one could complete primary and secondary school education and still marry early. Caudillo (2019) found evidence for this possibility in Mexico, where girls aged 10-17 who experienced advanced grade progression had early initiation of marriage. Nguyen and Lewis (2020) observed a similar result in Vietnam, noting that women who started schooling at a younger age were 5.5 times more likely to marry during adolescent years than those who delayed school enrollment. These findings suggest that the benefits of improved school completion rates (corresponding to improved completed years of schooling) in delaying union formation could be attenuated by improvements in age at school entry and grade progression rates, mainly if girls' opportunities to progress beyond secondary education are limited.

The second mechanism, the ideational hypothesis, is related to changing norms about the timing of marriage that comes with exposure to and acquisition of knowledge or ideas that challenges traditional family formation values (Caldwell 1980). In SSA, societies have unique customs and systems that govern collective behavior, including the timing of union formation (Mawere and Mawere 2010, Ogoma 2014). Education exposes young girls to new ideals and brings aspirations and opportunities that weaken these norms. For example, education could expose girls to new ideas about the adverse effects of early marriages on their physical and mental health. The importance of this mechanism is thus dependent on the magnitude of the influence that schooling offers in redefining individual perspectives, preferences, and values about marriage timing. Therefore, the education effect on marital timing would diminish if more girls complete their education without acquiring the necessary skills or knowledge (what other scholars have referred 
to as "enrollment without learning" (Bold, Filmer et al. 2017) that stimulate a desire to postpone marriages to later ages. This could lead to stalls or reversals in age at marriage for higher education groups as education become widespread and more women with "enrollment without learning" enter these classes.

More related to the ideational mechanisms is Becker (1973)'s economic theory of marriage, which argues that girls could use marriage as financial security or parents could marry their daughters early to shift the economic burden of raising them to their new spouses. Parents could also marry young girls sooner to mitigate economic shocks (Corno, Hildebrandt et al. 2020). As a human capital investment, education raises opportunities for girls to participate in wage employment, thus boosting their financial independence and reducing the need for an early marriage. Equally, educated parents are bound to be economically self-reliant, thus less likely to push their daughters into early marriages for economic gains. However, similarly to ideational mechanisms, the strength of the education effect on union formation modulated by economic forces is likely to depend on knowledge and skills that one develops in school, and the growth of economies as education becomes widespread. If young girls who complete primary and secondary education lack the opportunity to join wage employment (either because of limited skills or limited employment opportunities), early marriage could still be an alternative pathway to financial security. In this case, expansion of female education could lead to stalls or reversals in age at marriage for these education groups via lowered employment opportunities as more women gain education and compete for wage labour.

\section{The sub-Saharan Africa context and research hypotheses}

SSA countries witnessed a substantial increase in girls' school participation over the last three decades. Data from DHS indicate that during 1990-99 1 period, on average, $52.1 \%$ of women aged 15-49 had ever attended at least primary school in this region. Only $17.0 \%$ had secondary or higher education. Since then - a period of 30 years - girls' school participation, particularly in primary and secondary school, has expanded markedly. For example, during $2010-19^{2}$ period, $70.2 \%$ of females aged 15-49 had at least primary education, and $40.3 \%$ attended secondary school. However, girls' participation in college education lagged, with only $5.2 \%$ of women aged 15-49 reported to have attained tertiary education during 2010-19. These averages obscure persisting regional heterogeneity in both timing, level and pace of female education expansion. In broad terms, countries in Southern Africa (e.g. Botswana, Namibia and South Africa) are precursors of this transition. For example, Frye and Lopus (2018) showed that in three-fourth of countries in West Africa, the proportion of women who ever attended school among women born between 1980 and 1990 was far less than women born in the 1940s in Southern Africa. The pattern

\footnotetext{
${ }^{1}$ Authors calculation based on earliest DHS data collected between 1990 and 1999 in SSA

${ }^{2}$ Authors calculation based on most recent DHS data collected between 2010 and 2019 in SSA
} 
of girls' school participation in most Central and East African countries lies between West and Southern Africa (Frye and Lopus 2018).

The expansion of girls' school participation in SSA coincided with improvements in school completion rates. For example, Evans and Mendez Acosta (2021) estimated that the primary school completion rate increased from $40 \%$ to nearly $60 \%$ between 1975 and 2015 . This shift means that, on average, women who attended school in recent years spent more years in school than women from previous generations. According to the incompatibility hypothesis, one would thus anticipate this progress to shift union formation to later ages.

On the other hand, female education expansion in SSA is marked with declines in age at school entry and falling grade repeating rates (Ndaruhutse 2008, Lucas and Mbiti 2012, Grant 2015, World Bank 2020 ). Thus, women from recent birth cohorts are more likely to have graduated from primary or secondary school at relatively younger ages than those born some generations ago. As argued above, such patterns are likely associated with early marriages, mainly when college education prospects are limited, as in most SSA countries. Thus, female participation in wage employment is probably the most efficient pathway to keep young girls who have graduated from primary or secondary education from early marriages in this region. However, the growth of economies in SSA did not keep up with increasing girls' school participation, such that the supply of primary or secondary school leavers now exceeds the labour market demand (AlSamarrai and Bennell 2007, Filmer and Fox 2014). Thus, in many SSA countries, early marriages may be perceived as practical means to girls' financial security, even among those who have completed primary or secondary education. Furthermore, SSA witnessed a deterioration of education quality in recent decades (Bold, Filmer et al. 2017, Filmer, Rogers et al. 2020, Evans and Mendez Acosta 2021), mainly due to the influx of schools following free primary education. For example, students complete their primary schooling in some countries without attaining the necessary reading and writing skills (Bold, Filmer et al. 2017).

The prevailing conditions linked to female education expansion in SSA, taken together with the incompatibility, ideational and economic hypotheses discussed above, lead us to draw three premises concerning how age at marriage for specific education groups might have evolved in parallel to levels of girls' school participation. Hypothesis 1 is that age at marriage stalled over some birth cohorts at the population level and that such patterns primarily rose from stalls and reversals in marital timing across specific education groups. Hypothesis 2 is that age at marriage stalled or reversed among women with primary and secondary education, particularly over birth cohorts for which the composition of these groups increased substantially. Finally, hypothesis 3 is that the overall change in the education group composition increased marriage rates. Further, as more women attained higher levels of education, the gains in age at marriage due to improvements in school completion rates were likely attenuated by changes in the composition of women from rural areas in each education group. The availability of DHS data in SSA, which contains marriage histories of women born as early as 1936, offers the possibility to assess these hypotheses and shed 
more insight on the nexus between expanded female education and the timing of union formation in SSA.

\section{Data and Methods}

\section{Data}

Data for this study comes from the Demographic Health Surveys (DHS) conducted between 1986 and 2019 in sub-Saharan Africa. DHSs are a series of cross-sectional studies introduced in the 1980s and early 1990s in most SSA countries. They are the most used, reliable and nationally representative information about demographic, socioeconomic, reproductive health and family formation in this region. DHS asks two key nuptiality questions essential to our current analysis: first, whether a woman has ever married or lived with a man as married, and second, the date at which such unions are first formed. Women with formal or informal unions are identified as ever married-a desirable flexibility since marriage formation is more of a process than an event in this region (Meekers 1992, Chae 2016). To date, DHS has collected marriage histories from women who were born as early as 1936 . Thus, they are ideal for assessing long term changes in marital behavior. This analysis includes 139 surveys from 34 countries. The pooled sample from all 34 countries consists of 1,462,867 women aged 15-49. We have grouped these countries into four major geographical regions (West, Central, East and Southern Africa) following a common classification in the literature (See, for example, United Nations Sustainable Development Goals Regions (United Nations 2019)) (Appendix 1). While single country estimates reveal more detail, commonalities in family formation behavior across these four broader regions justify the groupings and allow larger sample sizes than single country estimates. Nevertheless, we have produced country-specific estimates for some of the analyses and presented these in Appendix 2.

\section{Measures and methods}

The first goal of this paper is to document long term education-specific cohort changes in age at first marriage and assess how the emerging patterns (increase, stalls or reversals) are aligned with trajectories of female education expansion. We have identified education groups based on the DHS classification of respondents' highest level of education at the survey, which consists of four distinct categories: No formal schooling for those who never attended school, Primary for those who only had some primary education, Secondary for those who had up to secondary education, and Tertiary for women who acquired at least some college education. We restrict the analysis to the first three groups, as female education expansion was confined mainly to primary and secondary levels in most SSA; thus, the sample size of women with tertiary education is small in most countries. Furthermore, the analysis is limited to women aged $20+$ to exclude those who were still in primary school at the time of the survey but might attain secondary education later in their life course. 
The cohorts are defined based on the year of birth. In the pooled sample, the oldest woman was born in 1936 and the youngest in 2005. We classify women in each region and education group into five-year birth cohorts. Thus, those born before 1939 and after 2004 are dropped from the analysis. Assessment of the quality of marriage histories in DHSs reveals that older women tend to shift their age at first marriage towards the date of the survey (Gage-Brandon 1995, Mensch, Grant et al. 2006). This forward displacement of marriage events may lead to small changes in marital timing over birth cohorts and thus affect the patterns that one observes. To alleviate this problem, we produce estimates of marital timing for each birth cohort from a pooled sample of women born during the same period but interviewed at different survey points (i.e. at different ages). Thus, the measures are generally a weighted average of marriage histories reported at younger, middle or older ages. Hence, the forward displacement problem is likely to have minimal if any effect. In addition, to ensure reliable and stable estimates, we exclude all birth cohorts with a sample size of fewer than 200 women from the analysis. The final sample sizes for each region/country and birth cohorts are shown in Appendix 1.

Our measure of marital timing is the median age at first marriage. We calculate this estimate for each birth cohort and education group using event history analysis techniques. The event of interest is defined as entering into the first formal or consensual union. The age at which such events occur marks the survival time before transitioning from a single to married state. Thus, women who are not married at the survey date are right-censored. Marriages are quite early in SSA. Therefore, we measure the transition process from age 10 on a continuous time scale. We use the Kaplan Meier estimator to derive a survival function $S(t)$ of first marriage that fully accounts for the censoring in the data. Thus, in this study, the function $S(t)$ measures the proportion of unmarried women by time $t$ since age 10 . Therefore, the median age at first marriage is calculated as $t+10$ where $S(t)=0.5$.

To objectively examine changes in these median estimates over birth cohorts, we define stalls to correspond to intervals where at least three consecutive birth cohorts have median estimates with overlapping 95\% confidence intervals and a slope ranging between -0.01 and 0.01 . The selection of these cutting points is arbitrary; nevertheless, we aimed at cutting points close to zero to ensure we indeed capture stalls. Furthermore, we define an increase in median age at first marriage to refer to intervals where the median estimates for at least three consecutive birth cohorts increased monotonically with a slope of greater than 0.01 . Similarly, reversals correspond to intervals for which median age at marriage consistently decline at least for three consecutive birth cohorts with a slope of less than -0.01 .

The second component of this study focuses on understanding factors central to cohort differences in education-specific marriage rates. Our interest is to assess how the composition of the educational groups (not changes in the educational composition of the population) and marital behavior within education groups varied over birth cohorts and the extent to which such changes explain the direction and magnitude of cohort differences in marriage rates. We use a multivariate 
decomposition approach for nonlinear models (Fairlie 2005, Powers, Yoshioka et al. 2011) to address these questions. This technique involves specifying a regression model to decompose group differences (or differences over time) in proportions, counts or rates into a component due to differences in composition and a component due to changes in behavior (return to risk). In our case, the groups are birth cohorts, and we aim to decompose differences in first marriage rates for women with primary and secondary education separately. Within each education group over birth cohorts, we consider composition heterogeneity in rural vs urban residence and complete vs incomplete educational level. The latter variable was collected only for surveys conducted after 1989. Thus, we restrict this part of the analysis to surveys conducted between 1990 and 2019. The majority of women (96\%) surveyed during this period were born between 1950 and 1994. Therefore, we consider these women and classify them into three 15-year birth cohorts (1950-64, 1965-79 and 1980-94). Thus, we run two decomposition models for each of the four regions and education level, first comparing 1950-64 with the 1965-79 birth cohort and second comparing 1950-64 with the 1980-94 birth cohort (in both cases, 1950-64 is the comparison group).

The process time for this part of the analysis is measured on a discrete time scale. Thus, we have used a discrete-time logit regression model for the decomposition, where the logit of the baseline hazard is a linear function of the process time split into single year sub episodes - i.e.

$\log \left(\frac{\lambda_{j}(t)}{1-\lambda_{j}(t)}\right)=\boldsymbol{\alpha}(t)+\boldsymbol{\beta}_{1}$ residence $+\boldsymbol{\beta}_{2}$ edu. complete

where $\lambda_{j}(t)$ is the risk of first marriage at time $\mathrm{t}$ for an individual $\mathrm{j}, \beta_{1}$ and $\beta_{2}$ are coefficients associated with the area of residence and education completion status (edu.complete), respectively. The parameter $\boldsymbol{\alpha}(t)$ is defined as:

$\boldsymbol{\alpha}(t)=\sum_{t(a g e)=10}^{\tau} \alpha_{t} \omega_{t}$

where $\omega_{t}$ 's are dummies for the single-year sub episodes of the process time and $\alpha_{t}{ }^{\prime} s$ are associated coefficients.

The process of a multivariate decomposition analysis involves fitting a specified regression model to groups under consideration separately. For example, when comparing the 1950-64 and 1965-69 birth cohorts, the process would involve fitting the model we specified to these two birth cohorts separately and using the resulting coefficients to estimate the difference in marriage rates due to composition changes and a component due to differences in coefficients. For that reason, the fitted models must include an equal set of predictors. However, this condition is not possible in our decomposition models when we consider a full range of observable process time available in the data (i.e. from age 10 to 49) because none of the women born during 1980-94 had reached age 41 at the time of the survey. It means that $\omega_{t}$ correspond to dummies for single-year sub 
episodes ranging from age 10 to 49 for the older cohorts but not for the 1980-94 birth cohort. We address this problem by modifying the process time to start at age 10 and end at 30 . The cohort differences in marriage rates we decompose thus relate to marriage rates between age 10 and 30 .

We perform all the decomposition analyses using the $m v d c m p$ command available in Stata software (Powers, Yoshioka et al. 2011). In addition, all the independent variables are normalized to ensure that the results are invariant with the reference category option.

\section{Results}

Cohort changes in the proportion of unmarried women by age according to the level of education in four SSA Regions

Figure 1 shows the proportion of women still unmarried by age according to birth cohorts. Moving along the columns, we show these estimates for women with the same level of education across four SSA regions, while moving from left to right show these estimates according to level of education within the same region. The slope of each line (how quickly the survival function drops) indicates the pace of marriage formation relative to age. The sooner the first unions are formed, the steeper the slope. At a given age, the spread of these lines indicates the magnitude of change of the proportion of women married at that specific age over birth cohorts: the wider the spread, the more significant the difference.

The first column panel in Figure 1 shows the estimates corresponding to all women (all education groups combined). The lines representing younger cohorts in this panel fall gradually and lie above those of older cohorts, thus confirming that marital timing is shifting to older ages among the recent birth cohorts across all the regions. However, in West, Central and East Africa, the timing rather than the quantum of first marriage substantially changed. The spread of the survival curves at a given age is more pronounced between ages 17 and 30 in these regions, and they generally converge at ages above 35 . For example, the proportion of women married by age 20 declined from $77.1 \%$ among the 1940-44 birth cohort to 54.5\% for women born during 199599 in West Africa. This change is from $83.6 \%$ to $52.7 \%$ in Central Africa and $74.2 \%$ to $53.2 \%$ in East Africa. In contrast, the proportion of women married by age 35 nearly remained above $95 \%$ between the 1950-54 and 1980-84 birth cohorts. Southern Africa is generally different. In this region, first marriages were already postponed to later ages among women born as early as the 1950s. For example, the proportion of women married by age 20 was only $30.2 \%$ for women born during 1950-54, and about $22.3 \%$ of women of this cohort were still unmarried at age 35 . 
Figure 1: Proportion of unmarried women by age according to birth cohort and level of education in four sub-Saharan Africa regions

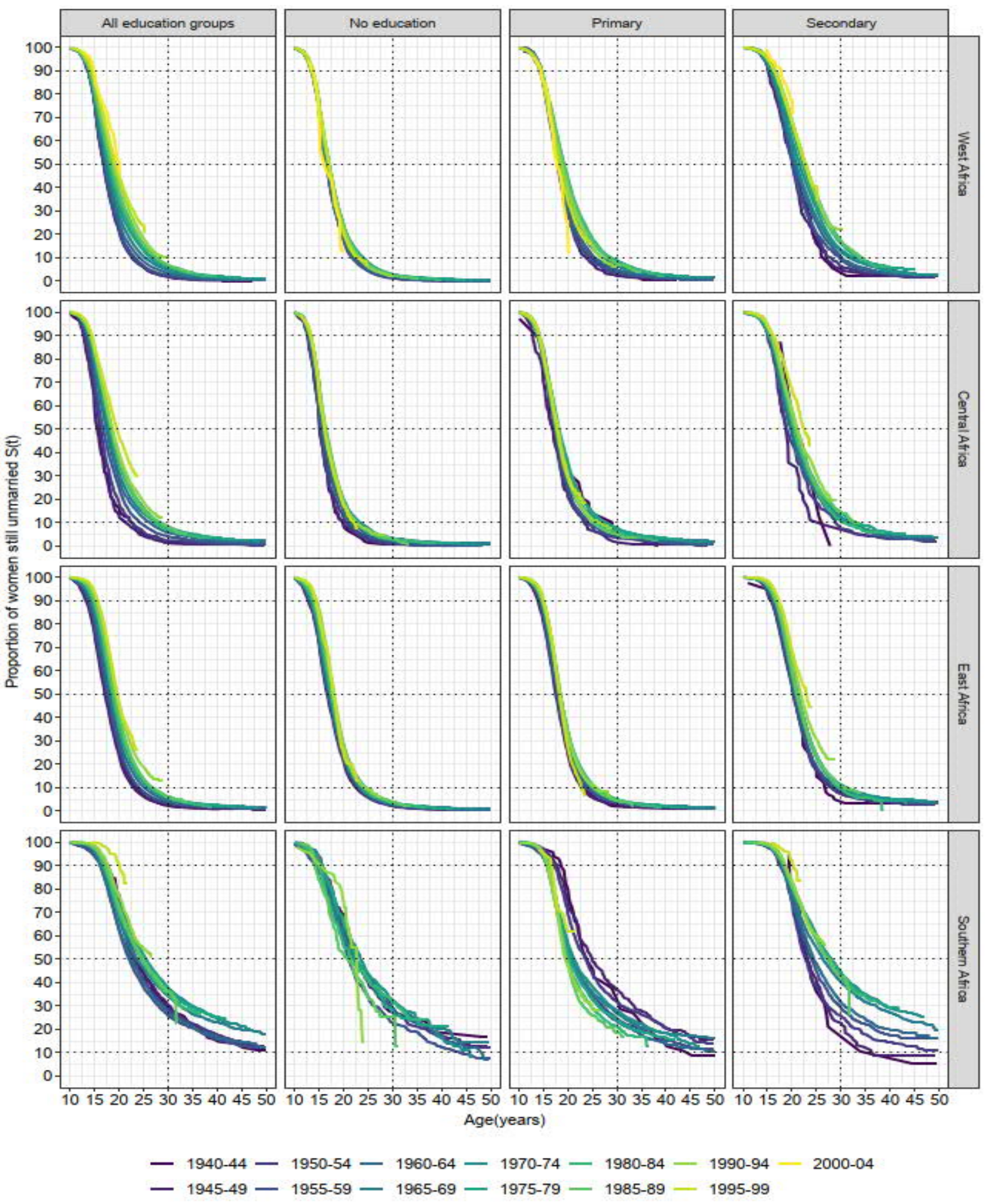

Source: Demographic Health Survey data available in 34 sub-Saharan Africa countries, 1986-2019. 
For specific education groups (second to fourth column panel), marital timing has changed more among women with secondary education across all the regions. Nevertheless, in West, Central and East Africa, the proportion of unmarried women is almost less than 5\% at age above 35 for all education groups, thus indicating that marriage is still universal irrespective of education level in these regions. For Southern Africa, the proportion of women who eventually marry by age 35 has dropped significantly among women with secondary education than in other education groups. Thus, it appears that women with secondary education rather than those with primary or no education are increasingly abstaining from forming first unions in this region.

Cohort changes in median age at first marriage by level of education during female education expansion in four SSA regions

In Figure 2, we present the median age estimates of the survival lines shown in Figure 1 together with changes in the education composition of women over birth cohorts. The background area in Figure 2 shows the percentage of women with no education (light grey bottom area), primary education (middle grey area) and secondary education (dark grey top area) among women aged $20+$ in each birth cohort. The median age at first marriage (with their $95 \%$ confidence intervals) for each education group are presented using lines, with their corresponding scale shown on the right-hand side. We present a similar figure showing country-specific results in Appendix 2.

Figure 2 reveals three key findings concerning the evolution of marital timing during female education expansion. First, the results show that median age at first marriage at the population level (among all women) stalled over some birth cohorts in West, Central and East Africa, and it reversed in Southern Africa. In West Africa, the median age at first marriage was 17.0 for women born during 1945-49. It increased to 17.5 for the 1965-69 birth cohort, stalled around 18.0 between the 1970-74 and the 1980-84 birth cohorts, and then increased to 19.1 among women born during 1995-99. In Central Africa, the median age at first marriage rose from 15.8 for the 1945-49 birth cohort to 18.5 for the 1975-79 birth cohort. It stayed around 18.5 until the 1990-94 birth cohort before rising to 19.7 among women born during 1995-99. For East Africa, median age stalled at 18.8 between 1970-74 and 1980-84 birth cohorts after increasing from 17.3 among women born during 1945-49. It later increased to 19.8 for the 1995-99 birth cohort. The reversal in age at marriage in Southern Africa occurred among women born after 1980-84. Previously, it had risen from 22.7 among the 1945-49 birth cohort to 25.2 for women born during 1970-74. At the country level, reversals in age at marriage among all women are evident in Comoros, Congo, and Madagascar, and dominant stalls are apparent in countries such as Benin, Burkina Faso, Burundi, Chad, Congo (DRC), Cote d'Ivoire, Kenya, Malawi, Rwanda, Senegal, Uganda and Zimbabwe. 
Figure 2: Cohort changes in median age at first marriage by level of education during female education expansion in four sub-Saharan Africa regions

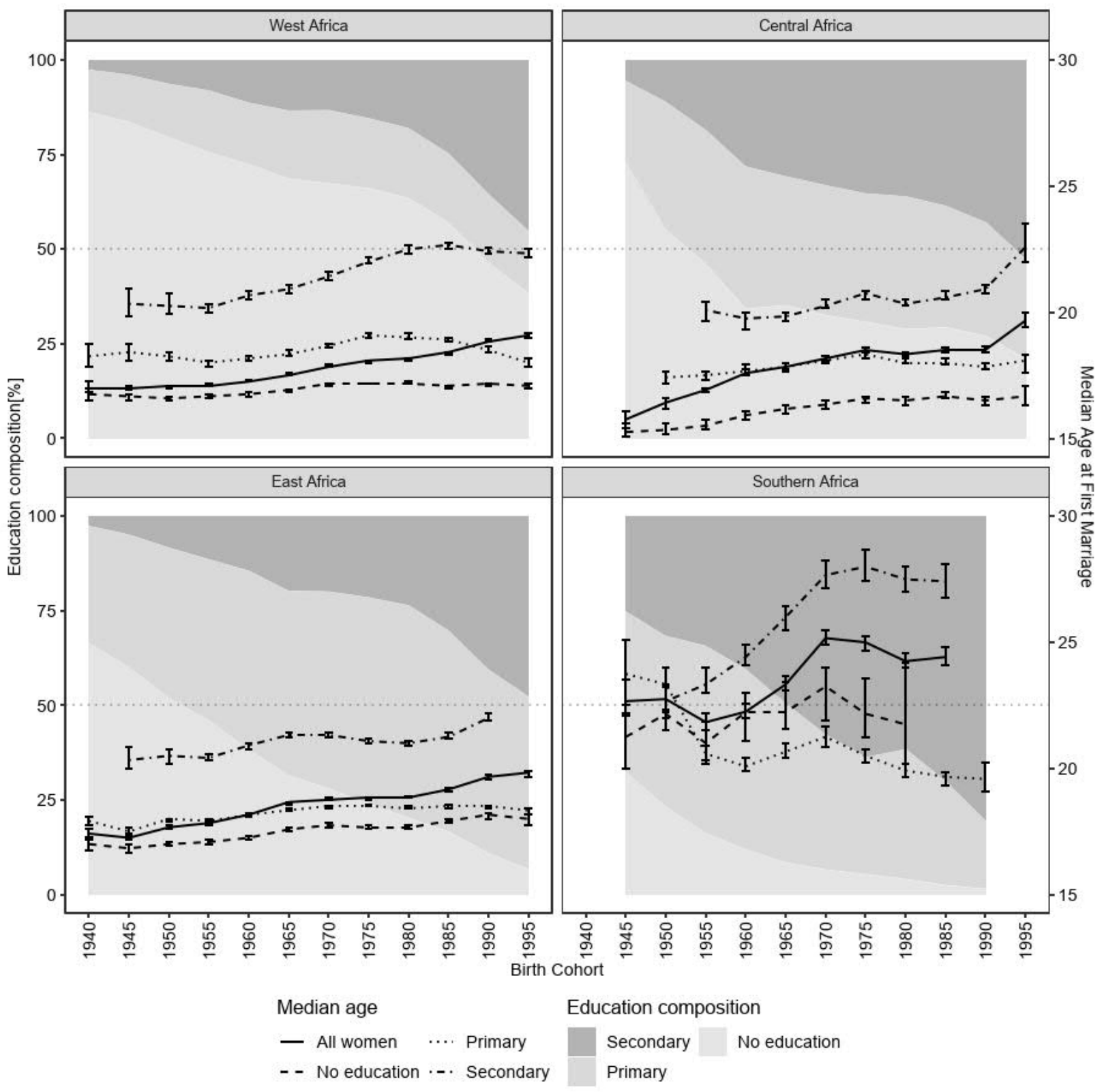

Note:

1. The background area shows the percentage of women with no education (light grey bottom area), primary education (middle grey area) and secondary education (dark grey top area) among women aged 20+ in each birth cohort. The median age at first marriage (with their $95 \%$ confidence intervals) for each education group are presented using lines, with their corresponding scale shown on the right-hand side.

2. Source: Demographic Health Survey data available in 34 sub-Saharan Africa countries, 1986-2019.

Second, 
Figure 2 illustrates that stalls in age at marriage at the population level rose from a combination of stalls and reversals in marital timing across all education groups - i.e. age at marriage either stalled or reversed over some birth cohorts for all education groups across all the four regions. For example, in Southern Africa, a reversal in age at marriage among all women occurred over the same birth cohorts, for which median age at marriage declined among women with no education and stalled for women with secondary education. In East Africa, on the other hand, the stall in age at marriage coincided with a decline in age at marriage among women with secondary education and a stalling pattern for those with no formal schooling and primary education. The country-specific estimates in appendix 2 show that age at marriage either stalled or declined among women with primary or secondary education in 15 of the 33 SSA countries (Angola is excluded; see note in appendix 2). One critical feature about these dynamics is that stalls and reversals in education-specific marital timing (especially in West, Central and East Africa) translated into intervals of stalls at the population level, essentially when the proportion of women attaining secondary education changed moderately. The importance of girls' secondary education participation in driving median age at marriage at the population level is remarkably evident in West Africa. Median age at marriage among all women increased sharply in this region, starting with the 1980-84 birth cohort, despite stalling among women with no formal schooling and secondary education and reversing among women with primary education. This is because the proportion of girls who attended secondary education was sharply rising over these birth cohorts.

Third, the results in Figure 2 demonstrates that stalls and reversals in age at marriage among the primary and secondary education groups corresponded to different stages or levels of female education expansion. In West Africa, the median age at first marriage for women with secondary education stalled around 22.5, as the percentage of women with secondary education started to exceed $15 \%$. For the primary education group, median age at marriage declined among women born after 1970-74, with the composition of this group varying around 18\%. The story is different for Central, East and Southern Africa, with Central and East Africa revealing more similar trajectories. In Central Africa, age at marriage stalled starting with women born 1975-79, at around 18.0 for those with primary, and around 20.3 for women with secondary education. These stalls occurred when the composition of women with primary education dropped from 34.3 to 26.2 , and of those with secondary education varied between 33.1 and 36.0. Interestingly, age at marriage for the latter group started rising again among women born after 1980-84, as its composition rose sharply. We see a parallel pattern in East Africa. There, age at marriage stalled around 18.5 for women with primary education when their composition varied between $45.6 \%$ and $56.1 \%$. It declined between 1965-69 and 1980-84 birth cohort among women with secondary education as the composition of this group ranged between $19.7 \%$ to $23.6 \%$. As in Central Africa, median age at marriage for the latter group increased sharply following the 1980-84 birth cohorts in parallel with its composition. In Southern Africa, the median age at first marriage is much later than in the other African regions across all education groups and birth cohorts. It stalled for women with 
secondary education at around 27.5, starting with the 1970-74 birth cohort when the composition of this group had reached $57.7 \%$. For women with primary education, it decreased starting with the same birth cohort.

\section{Drivers of cohort changes in education-specific marriage rates}

We now consider the decomposition analysis results that examined the contribution of changes in education group composition and behavior to cohort differences in marriage rates. The focus is on understanding how these two components varied as female education expanded and identifying a component that largely influenced education-specific marriage rates. We consider women with primary and secondary education for this analysis as they allow us to examine composition changes concerning school completion rates in addition to rural-urban composition differences. Table 1 shows these composition changes over birth cohorts. It presents the proportion of women who had completed primary/secondary education and women from rural areas within each education category. We note that the percentage of women with a completed level of education increased across all regions for both the primary and secondary categories, except for women with primary education in West Africa. For this group, school completion decreased over birth cohorts, which intrinsically points out increasing drop-out rates as girls' school participation increased. The largest increase in the completion rate for primary education is observed in Southern Africa, while for secondary education, it is observed in West Africa.

Table 1: Percentage of women with a complete level of education and in rural areas according to the level of education and birth cohort in four sub-Saharan Africa regions.

\begin{tabular}{|c|c|c|c|c|c|c|}
\hline & \multicolumn{3}{|c|}{ Primary } & \multicolumn{3}{|c|}{ Secondary } \\
\hline & $1950-64$ & $1965-79$ & 1980-94 & $1950-64$ & $1965-79$ & 1980-94 \\
\hline \multicolumn{7}{|l|}{ West Africa } \\
\hline$\%$ completed level & 40.6 & 35.2 & 29.3 & 18.4 & 28.4 & 35.5 \\
\hline$\%$ in rural area & 53.1 & 49.3 & 49.5 & 30.7 & 29.0 & 33.3 \\
\hline \multicolumn{7}{|l|}{ Central Africa } \\
\hline$\%$ completed level & 28.1 & 29.2 & 29.3 & 8.3 & 10.4 & 15.5 \\
\hline$\%$ in rural area & 56.4 & 57.6 & 61.4 & 25.0 & 25.2 & 24.7 \\
\hline \multicolumn{7}{|l|}{ East Africa } \\
\hline$\%$ completed level & 28.0 & 33.9 & 32.4 & 20.5 & 24.6 & 27.2 \\
\hline$\%$ in rural area & 77.4 & 78.7 & 79.2 & 45.3 & 47.5 & 49.7 \\
\hline \multicolumn{7}{|l|}{ Southern Africa } \\
\hline$\%$ completed level & 29.1 & 40.9 & 48.4 & 23.4 & 29.2 & 31.7 \\
\hline$\%$ in rural area & 66.1 & 70.4 & 73.3 & 32.4 & 41.2 & 43.9 \\
\hline
\end{tabular}

Source: Demographic Health Survey data available in 34 sub-Saharan Africa countries, 1986-2019 
The proportion of women from rural areas within each education group partially reflects the dynamics of education expansion to rural areas. However, the area of residence in our data is captured at the time of the survey. Hence it does not fully capture the extent to which rural-urban representation changed within specific education groups. This is because women who attend school in rural areas are more likely to migrate to urban areas to seek job opportunities or because of marriage. Nevertheless, Table 1 shows some possible minimum changes in the rural-urban composition over birth cohort within each education group, and we would be interested in understanding how these account for cohort differences in marriage rates. With that in mind, we see increases in the proportion of women from rural areas within primary and secondary education groups across all regions. The only exception is West Africa, among women with primary education where the proportion of women from rural areas decreased, and in Central Africa among women with secondary education where it remained nearly constant. The largest change in this estimate for both primary and secondary education groups is registered in Southern Africa.

To understand marital behavior changes within primary and secondary education groups over birth cohort, we show the marginal risk of first marriage in each group (estimated from the model we specified for decomposition analysis) according to school competition status (Figure 3(a)) and area of residence (Figure 3(b)). The solid line in Figure 3(a) represents complete, and the dotted line means incomplete education. We use the solid and open dots to represent primary and secondary education groups, respectively. The results in Figure 3(a) reveal three key findings, which are essential in our quest to understand how marital behavior changed as female education expanded and help us understand the decomposition analysis results later. First, we note that marital risk declined over birth cohorts irrespective of education completion status for both primary and secondary education groups. The only exception is Southern Africa, among women with incomplete education where it increased. Second, the marital risk gap between those with complete education relative to those with incomplete education declined in recent birth cohorts in West Africa, Central Africa (when we compare the 1950-64 and 1965-79 birth cohort) and Southern Africa (among the primary group). However, except in Southern Africa, these changes are driven by women with incomplete education marrying later or less (reflected by a steeper decline in marital risk), rather than women with complete education marrying sooner or more. Third, the marital risk among women with complete primary education born during 1980-94 is higher than their counterparts with incomplete primary schooling in West Africa. A parallel relationship is apparent in Southern Africa for both the 1950-64 and 1965-79 birth cohorts. This dynamic is potentially due to assortative mating in this region, where women with complete primary education may be more attractive partners on the marriage market than their counterparts with incomplete primary schooling. These findings are also evident when similar estimates are produced based on 5-year birth cohorts (Appendix 3). Overall, the results in Figure 3(a) indicate that, at an individual level, the marital risk of women with more years of schooling did not rise in recent birth cohorts. 
Figure 3: Cohort changes in marginal risk of first marriage according to education level completion status (Figure 3(a)) and according to area of residence (Figure 3(b)) for each education group in four sub-Saharan Africa regions

\section{Figure 3(a)}

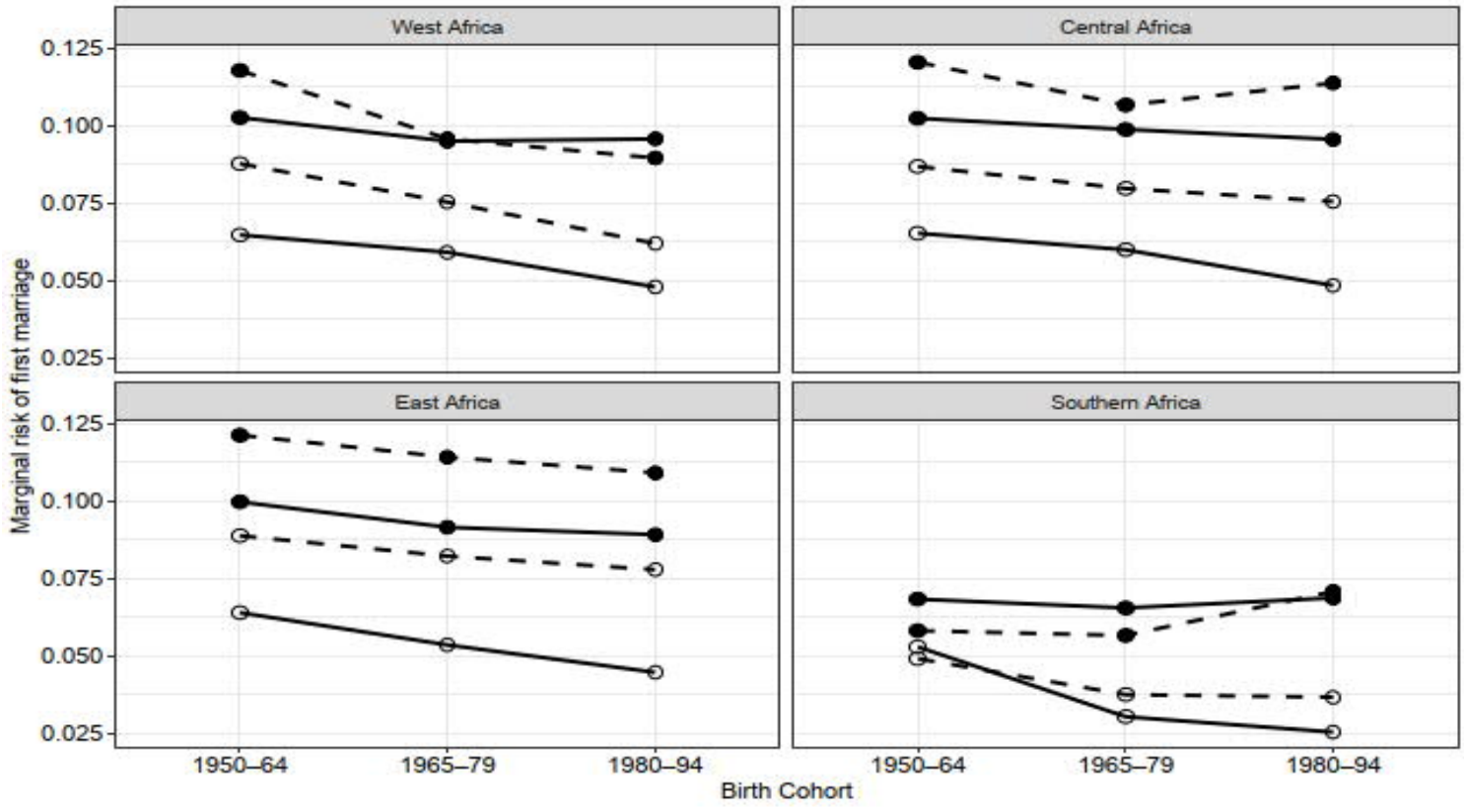

Figure 3(b)
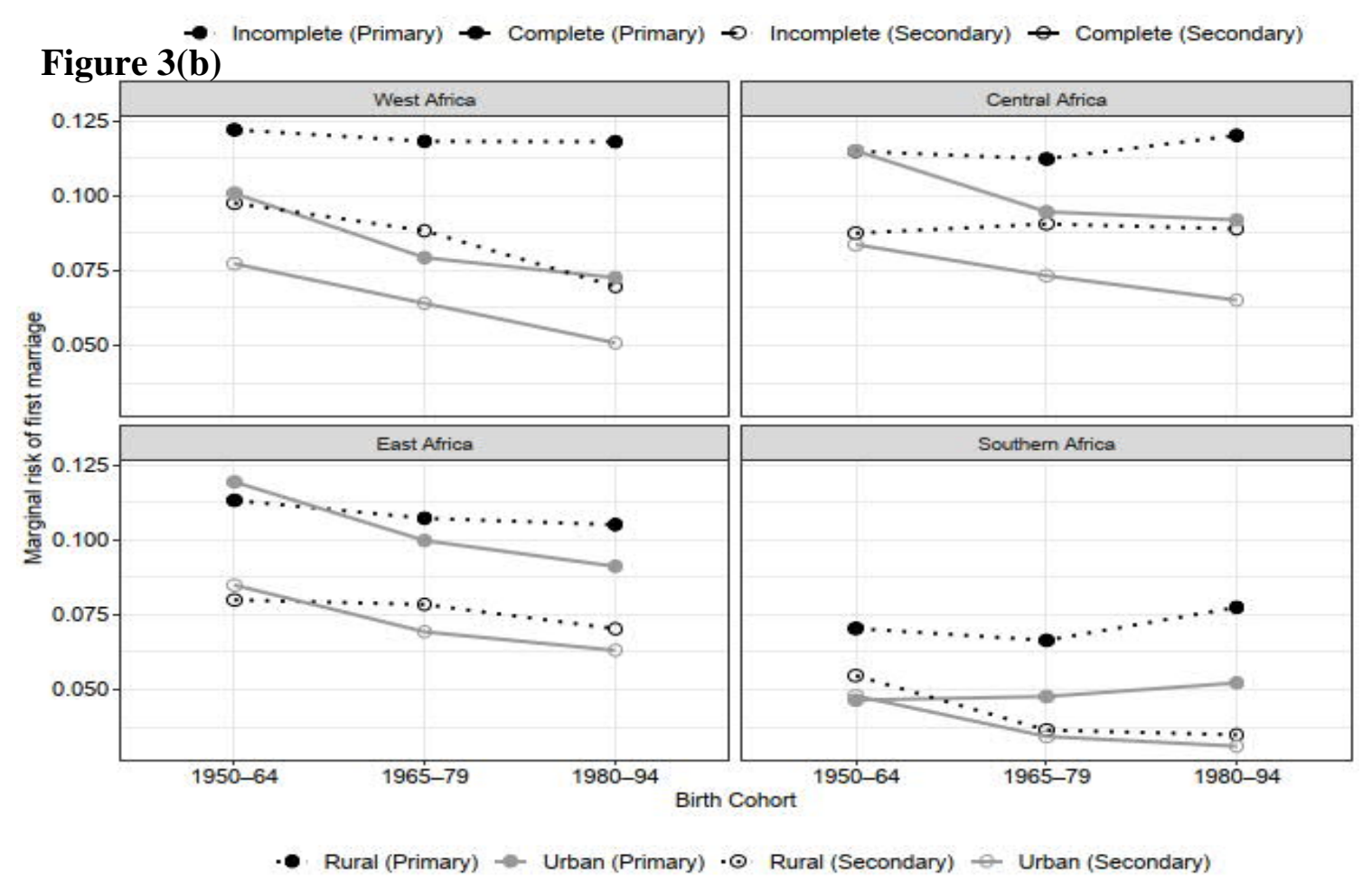

Source: Demographic Health Survey data available in 34 sub-Saharan Africa countries, 1986-2019. 
In the bottom panel of Figure 3 (Figure 3(b)), we show changes in marital risk for women in rural areas (dotted lines) and urban areas (solid grey line). Again, the solid and open dots represent primary and secondary education groups, respectively. In West, Central and East Africa, marriage risk dropped for women in urban areas, irrespective of the education level. The pattern is mixed for women from rural areas. Marriage risk only decreased substantially for women with secondary education in West Africa, while it increased for the remaining groups in the remaining two regions. In southern Africa, marriage risk dropped for the secondary group irrespective of the area of residence, while it increased for the primary group for both rural and urban, particularly between the 1950-64 and 1965-79 birth cohorts.

Figure 4. The contribution of changes in education group composition (Total composition component) and behaviour (Total effect component) to cohort differences in marriage rates (Overall change) for women with primary and secondary education in four sub-Saharan Africa regions

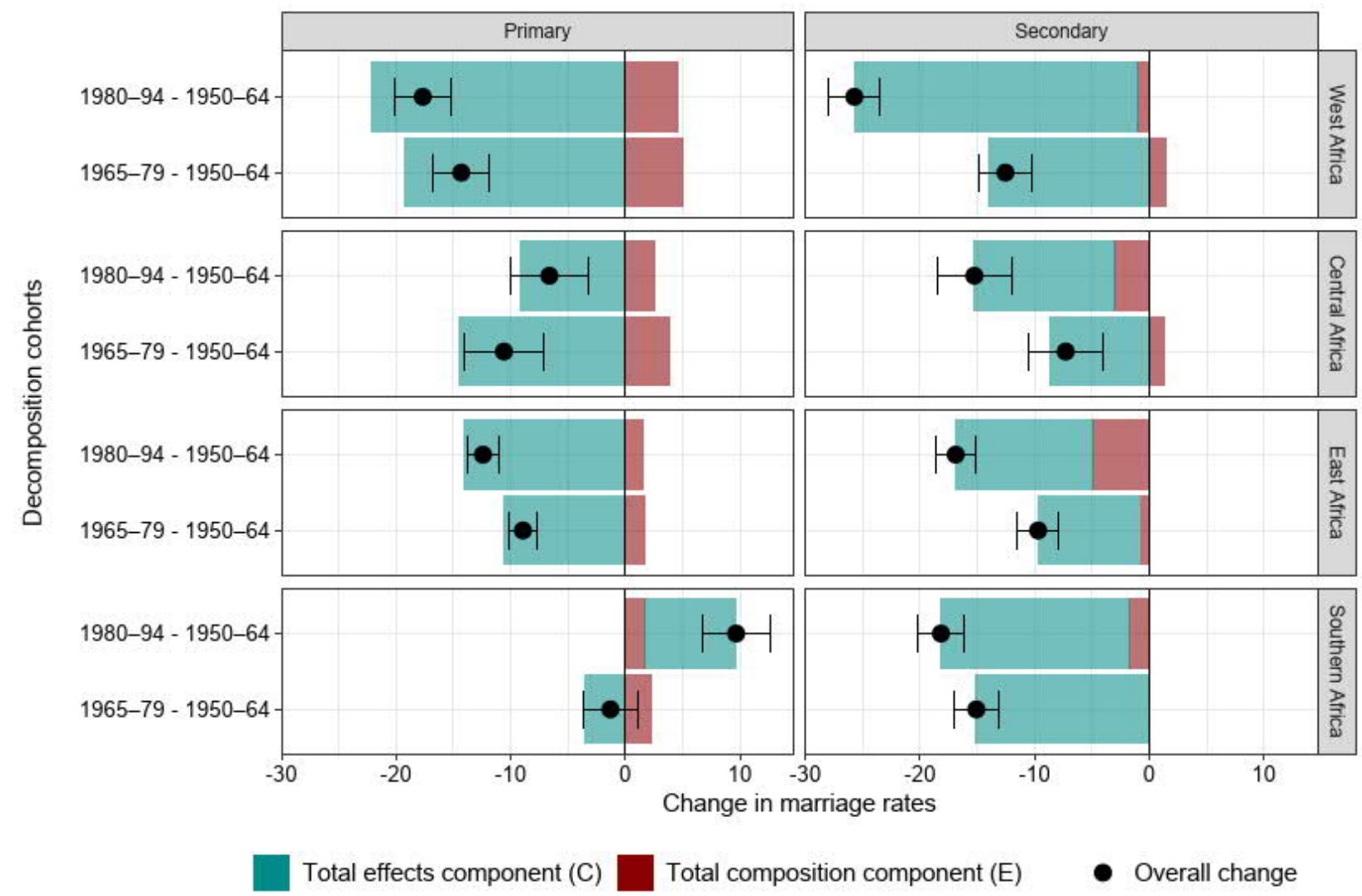

Note:

1. Marriage rate is estimated for the interval between age 10 and 30.

2. Source: Demographic Health Survey data available in 34 sub-Saharan Africa countries, 1986-2019. 
We show the overall contribution of the composition changes (Table1) and changes in marriage risk (Figure 3) to total cohort differences in marriage rates in Figure 4. The solid dots represent the absolute change in marriage rate (with 95\% CI) per age of year and 1000 women relative to the 1950-64 birth cohort. The green bar (Total effect component) represents the contribution to change in marriage rate due to changing marriage risk shown in Figure 3 (i.e. the contribution to cohort difference in marriage rate due to behavior change), while the red bar (Total composition component) represents the change in marriage rate due to changes in education group composition presented in Table 1.

Figure 4 shows that apart from women with primary education in southern Africa, marriage rates significantly declined in the recent birth cohorts across all four regions for both women with primary and secondary education. The largest decline in marriage rates is observed in West Africa for both education groups. A key finding in Figure 4 is that the decline in marriage rates are primarily driven by behavioral changes (effect component) and less so due to compositional changes. For the primary education group, composition change accounted for increases in marriage rates across all the regions. In West and Central Africa, compositional changes also contributed to increased marriage rates among women with secondary education when comparing the 1950-64 and 1965-79 birth cohorts. The detailed contributions to the overall change in marriage rates due to composition changes are presented in Appendix 4. As it should be expected, the increases in school completion rates accounted for decreases in marriage rates. The only major exception is Southern Africa among the primary education group, where the rise in completion rates over birth cohorts increased the marriage rate. This is because women with complete primary education in this region had a higher risk of marriage than those with incomplete primary education. In addition, the rise in the proportion of women from rural areas within specific education groups led to increasing marriage rates. This latter result should be expected because women from rural areas generally have a higher marriage risk (Figure 3(b)).

\section{Discussion and Conclusion}

We used data from 139 Demographic Health Surveys (DHS) collected in 34 sub-Saharan Africa (SSA) countries between 1986 and 2019 to achieve two specific objectives. First, to examine education-specific long-term cohort changes in age at first marriage and assess whether the emerging patterns (increase, stalls or reversals) were aligned with levels of girls' school participation. Second, to investigate the contribution of changes in education group composition and behavior to cohort differences in marriage rates for women with primary and secondary education. For the first objective, we applied the Kaplan Meier estimator to produce educationspecific median ages at first marriage for 5-year birth cohorts across four SSA regions. We then used a discrete-time logit regression model to perform a multivariate decomposition of cohort changes in marriage rates into a component due to compositional change and a portion due to behavioral changes to address the second objective. For this later analysis, we focused on marriage rates for ages between 10 and 30 to achieve a reasonable comparison between the early and recent 
birth cohorts. Nevertheless, it is essential to note that over $90 \%$ of women in West, Central and East Africa were married by age 30 across all birth cohorts. Thus, the decomposition analyses in these regions relate more to changes in marital timing and less to the quantum of marriage. However, in Southern Africa, the proportion married by age 30 was less than $80 \%$ across all birth cohorts. Thus, cohort differences in marriage rates are related to both the quantum and the timing of marriage in this region.

The findings we observed confirmed that median age at marriage at the population level (all education groups combined) stalled over some birth cohorts across all SSA regions. Previous research argued that such stalls could be linked to poor quality of education, changes in age pattern of school enrolment and completion, and loss of selectivity as more women attend school (Grant 2015, Bongaarts, Mensch et al. 2017). Thus, our hypothesis 1 stated that stalls in marital timing at the population level primarily rose from stalls and reversals in age at marriage across specific education groups. The results documented across all the four SSA regions confirmed this hypothesis. Median age at marriage stalled or reversed for all education groups over some birth cohorts in these regions. However, we observed that although stalls and reversals in age at marriage for specific education groups were important, they were not a necessary condition for stalls that emerged at the population level. It is instead the stalling in the composition of women who attended secondary education that mattered most. This finding is more apparent in West Africa among women born after 1980-84. Age at marriage over these birth cohorts stalled for women with no formal schooling and those with secondary education and reversed among women with primary education. However, this did not translate into stalls in median age at marriage at the population level because the proportion of women who attended secondary education rose markedly, and the education gradient in age at marriage was huge (5+ years between secondary and no education group, and 3.5+ years between secondary and primary education group). In contrast, in East Africa, for example, marital timing for specific education groups stalled among the cohorts born in 1965-69 and 1980-84, for which the composition of women attaining secondary education stagnated, and those attending primary education increased. These findings confirm that changes in female education composition are critical in shaping population-level marital timing trajectories (Bongaarts, Mensch et al. 2017). However, our results illustrate that the change in the composition of women with secondary education rather than primary education matters most.

Hypothesis 2 was that age at marriage stalled or reversed among women with primary and secondary education, particularly over birth cohorts for which the composition of these groups increased substantially. We observed mixed findings concerning this proposition. The results showed that stalls or reversals in age at marriage for these education groups corresponded to different stages of female education expansion across SSA regions. The most striking result is that stalls or reversals in marital timing for women with primary or secondary education did not necessarily occur over birth cohorts that experienced a substantial increase in girls school participation. Birth cohorts for which marked female education expansion also coincided with 
stalls or reversals in marital timing are mainly apparent in West Africa. In Central Africa, age at marriage stalled among women with secondary education between the 1970-74 and 1980-84 birth cohorts when the composition of this group varied between $33.1 \%$ and $36.0 \%$. However, it rose sharply following the 1980-84 birth cohort in parallel with a marked increase in the proportion of girls attaining this level of education. We noted a parallel pattern in East Africa. The age at marriage for women with secondary education declined between 1965-69 and 1980-84 birth cohort in this region, before rising alongside significant growth in the composition of this group. Women born after 1980-84 are presumably the most beneficiaries of the policies that promoted girls' school participation in the early 1990s. These are also birth cohorts that are supposedly assumed to have experienced the most deterioration in education quality due to the influx of schools (Bold, Filmer et al. 2017, Filmer, Rogers et al. 2020, Evans and Mendez Acosta 2021), the most improvements in early school enrolment and grade progression rates (Ndaruhutse 2008, Lucas and Mbiti 2012, Grant 2015, World Bank 2020 ) and limited employment opportunities outside the family (Al-Samarrai and Bennell 2007, Filmer and Fox 2014). Thus, the observation that age at marriage among women with secondary education increased over these birth cohorts in Central and East Africa suggest that these conditions (poor education quality e.t.c) might not be inevitably the central mechanism that influenced stalls in marital timing in SSA regions.

Finally, hypothesis 3 was that the change in education group composition led to increased marriage rates within education groups. This is ideally a proposition linked to the idea that little change in age at marriage at the population level might have arisen from declining selectivity of education groups as female education expanded. Our results support this hypothesis, although we found that rather than education group composition, behavior changes explained the largest component of cohort differences in marriage rates for both primary and secondary education groups. We observed that marriage rate would have slightly increased (particularly among women with primary education) if only composition had changed. For the secondary education group, composition changes contributed to slight declines in marriage rates, especially when comparing the 1950-65 and the 1980-94 cohorts.

Our assessment considered two composition dimensions within each education category: the school completion rate and the proportion of women from rural areas. Increasing school completion rates generally reduced marriage rates (the primary group in the Southern region is exceptional). Thus, the fact that marriage risk among women with primary education would have increased in most regions if only composition had changed suggests that improvements in primary school completion rates are not sufficient to delay marital timing in these regions. This observation provided further evidence that girls' school participation beyond primary is more relevant for delaying marital timing. For secondary education, improvements in school completion rates could lead to lower marriage rates. Nevertheless, it is clear from our findings that returns from such changes are likely to be minimal. Concerning rural-urban composition changes, we found that this did not change exceptionally across all the regions. Nevertheless, the impact of increasing school completion rates on marriage risk was offset in part by a growing number of women from rural 
areas. This gives some weight to the idea that as education becomes more accessible, education groups become more heterogonous, encompassing women with diverse values in union formation, which could lower marital timing. However, as we have argued, such dynamics appear to have mattered less in shaping education-specific union formation patterns in SSA.

It is worth noting a few aspects of marital timing patterns that emerged in Southern Africa. Age at marriage in this region was exceptionally high across all education groups relative to West, Central and East Africa. Besides, the pattern that emerged there appears more connected to the shifts of female education composition. We can highlight three striking features of this pattern. First, women with no education had a higher median age at first marriage than women with primary education. Second, the median age at first marriage among women with primary education continuously declined following the 1970-74 birth cohort. Third, the proportion of women who attended school was already high (exceeding 65\%) among women born during 1945-49 (the proportion of women with no education dropped to below $6.7 \%$ after the 1970-74 birth cohort (estimated at $0.8 \%$ for the $1990-94$ cohort)). This pattern suggests that women with no education had become more select in several aspects, which may have lowered their marriage risk than women with primary or secondary education. For example, we can consider the assortative mating mechanism. Previous studies have documented that this marriage arrangement is typical in Southern Africa (Kollamparambil 2020, Pesando 2021). Thus, in a context of high levels of education, women with no schooling are bound to be less privileged in finding a suitable match on the marriage market. On the other hand, the decline in median age at first marriage among women with primary education over the recent birth cohorts could reflect that this group had become selective to women with fewer aspirations for later marriages.

The results we have documented are largely descriptive and primarily illustrate whether and when marital timing for specific education groups stalled as female education expanded. The data we used is limited and not suitable for identifying the specific causal factors responsible for marital timing stalls in these education groups. Thus, collecting detailed life course data on the timing of marriage, school enrollment and completion, economic activity of girls following school completion, and the characteristics of the partners they eventually form unions with in future studies could help shed more insights into these dynamics.

Nevertheless, the findings presented in this paper are essential for consideration of future trajectories in marital timing in SSA for two reasons. First, several countries are at the early or middle stages of female education expansion. Thus, the idea that female education expansion could trigger stalls in the timing of early reproductive events might be troubling for policymakers. While we indeed found that female education expansion could be associated with marital timing stalls among women with primary and secondary education (as observed in West Africa), our findings also demonstrate that age at marriage is not certainly bound to stall or reverse as girls school participation increases (as illustrated in Central and East Africa). The current data do not permit an in-depth analysis of these regional differences; thus, we cannot isolate specific conditions attached to female education expansion that could yield stalls in marital timing for specific 
education groups and those that do not matter. Future research could consider addressing this gap. Nevertheless, even under the conditions that produced stalls and reversals in age at marriage for the specific education groups in West Africa, marital timing at the population level could still increase (as it evolved there) if more women attain secondary education. Thus, we argue that further delays in age at first marriage at the population level, at least in West, Central and East Africa, would largely depend on increasing the number of females attending secondary education rather than only improving primary school participation or just primary school completion rates. However, improvements in completion rates for women enrolling in secondary schools could somewhat contribute to further delays in marital timing in these regions. Thus, countries should consider initiatives that promote girls' school participation beyond primary education and ensure higher completion rates among those enrolling in secondary schools. Second, with increasing female education, more countries would soon be attaining universal primary and secondary education. Appendix (2) results reveal that some countries (e.g. Zimbabwe) are already reaching these stages, but marital timing remains relatively early. Ideally, further improvement in age at marriage in such countries would mainly depend on education group behavior changes. Thus, the fact that behavior changes were central for cohort differences in education-specific marriage rates is a beam of hope for future marital trajectories in these regions. 


\section{References}

Al-Samarrai, Samer, and Paul Bennell. 2007. Where has all the education gone in sub-Saharan Africa? Employment and other outcomes among secondary school and university leavers. The Journal of Development Studies 43(7): 1270-1300.

Althabe, Fernando, Janet L. Moore, Luz Gibbons, Mabel Berrueta, Shivaprasad S. Goudar, Elwyn Chomba, Richard J. Derman, Archana Patel, Sarah Saleem, Omrana Pasha, Fabian Esamai, Ana Garces, Edward A. Liechty, K Michael Hambidge, Nancy F. Krebs, Patricia L. Hibberd, Robert L. Goldenberg, Marion Koso-Thomas, Waldemar A. Carlo, Maria L. Cafferata, Pierre Buekens \& Elizabeth M. McClure. 2015. Adverse maternal and perinatal outcomes in adolescent pregnancies: The Global Network's Maternal Newborn Health Registry study. Reproductive health 12(2): 1-9.

Becker, Gary S. 1973. A theory of marriage: Part I. Journal of Political economy 81(4): 813-846.

Bold, Tessa, Deon Filmer, Gayle Martin, Ezequiel Molina, Brian Stacy, Christophe Rockmore, Jakob Svensson, and Waly Wane. 2017. Enrollment without learning: Teacher effort, knowledge, and skill in primary schools in Africa. Journal of Economic Perspectives 31(4): 185-204.

Bongaarts, John, Barbara S. Mensch, and Ann K. Blanc. 2005. Trends in the age at reproductive transitions in the developing world: The role of education. Population studies 71(2): 139-154.

Caldwell, John C. 1980. Mass education as a determinant of the timing of fertility decline. Population and development review 6(2): 225-255.

Caudillo, Mónica L. 2019. Advanced school progression relative to age and early family formation in Mexico. Demography 56 (3): 863-890.

Chae, Sophia. 2016. Forgotten marriages? Measuring the reliability of marriage histories. Demographic research 34(19): 525-562

Clark, Shelley, and Sarah Brauner-Otto. 2015. Divorce in sub-Saharan Africa: Are unions becoming less stable? Population and Development Review 41(4): 583-605.

Corno, Lucia, Nicole Hildebrandt, and Alessandra Voena. 2020. Age of marriage, weather shocks, and the direction of marriage payments. Econometrica 88(3): 879-915.

Evans, David K., and Amina Mendez Acosta. 2021. Education in Africa: What Are We Learning? Journal of African Economies 30(1): 13-54.

Fairlie, Robert W. 2005. An extension of the Blinder-Oaxaca decomposition technique to logit and probit models. Journal of economic and social measurement 30(4): 305-316. 
Filmer, Deon, and Louise Fox. 2014. Youth employment in sub-Saharan Africa. World Bank Publications.

Filmer, Deon, Halsey Rogers, Noam Angrist and Shwetlena Sabarwalet al. 2020. Learningadjusted years of schooling (LAYS): Defining a new macro measure of education. Economics of Education Review 77: https://doi.org/10.1016/j.econedurev.2020.101971

Frye, Margaret, and Sara Lopus. 2018. From privilege to prevalence: Contextual effects of women's schooling on African marital timing. Demography 55(6): 2371-2394.

Gage-Brandon, Anastasia J. 1995. An assessment of the quality of data on age at first union, first birth, and first sexual intercourse for Phase II of the Demographic and Health Surveys Program. Macro International Incorporated

Garenne, Michel. 2004. Age at marriage and modernization in sub-Saharan Africa. Southern African Journal of Demography 9(2): 59-79.

Glynn, Judith R., Bindu S. Sunny, Bianca DeStavola, Albert Dube, Menard Chihana, Alison J. Price and Amelia C. Crampin. 2018. Early school failure predicts teenage pregnancy and marriage: A large population-based cohort study in northern Malawi. PloS one 13(5): e0196041. https://doi.org/10.1371/journal.pone.0196041.

Grant, Monica J. 2015. The demographic promise of expanded female education: trends in the age at first birth in Malawi. Population and development review 41(3): 409-438.

Grønvik, Taran, and Ingvild Fossgard Sandøy. 2018. Complications associated with adolescent childbearing in Sub-Saharan Africa: A systematic literature review and meta-analysis. PloS one 13(9) : e0204327. https://doi.org/10.1371/journal.pone.0204327

Hertrich, Véronique. 2017. Trends in age at marriage and the onset of fertility transition in subSaharan Africa. Population and Development Review 43(1): 112-137.

ICF. 2015. The DHS Program STATcompiler. Available: http://www.statcompiler.com. (Accessed: 31 May 2021)

Jejeebhoy, Shireen J. 1995. Women's education, autonomy, and reproductive behavior: Experience from developing countries. OUP Catalogue. Oxford University Press

Kidman, Rachel. 2017. Child marriage and intimate partner violence: a comparative study of 34 countries. International journal of epidemiology 46(2): 662-675. 
Kollamparambil, Umakrishnan. 2020. Educational homogamy, positive assortative mating and income inequality in South Africa: An unconditional quantile regression analysis. The Journal of Development Studies 56(9): 1706-1724.

Lloyd, Cynthia B., and Barbara S. Mensch. 2008. Marriage and childbirth as factors in dropping out from school: an analysis of DHS data from sub-Saharan Africa. Population studies 62(1): 113.

Lucas, Adrienne M., and Isaac M. Mbiti. 2012. Access, sorting, and achievement: The short-run effects of free primary education in Kenya. American Economic Journal: Applied Economics 4(4): 226-53.

Mawere, Munyaradzi, and Annastacia Mbindi Mawere. 2010. The changing philosophy of African marriage: The relevance of the Shona customary marriage practice of Kukumbira. Journal of African Studies and Development 2(2): 224-233.

Meekers, Dominique. 1992. The process of marriage in African societies: A multiple indicator approach. Population and development review 18(1): 61-78.

Mensch, Barbara S., Monica J. Grant, and Ann K. Blanc. 2006. The changing context of sexual initiation in sub-Saharan Africa. Population and development review 32(4): 699-727.

Mensch, Barbara S., Susheela Singh, and John B. Casterline. 2005. Trends in the timing of first marriage among men and women in the developing world. The changing transitions to adulthood in developing countries: Selected studies, National Academies Press: 118-171.

Ndaruhutse, Susy, Laura Brannelly, Michael Latham. 2008. Grade repetition in primary schools in Sub-Saharan Africa: an evidence bases for change. United Kingdom: CfBT Education

Nguyen, Hieu TM, and Blane D. Lewis. 2020. Teenage Marriage and Motherhood in Vietnam: The Negative Effects of Starting School Early. Population Research and Policy Review 39(4): 739-762.

Ogoma, Daniel Ebun. 2014. Reflection on an African traditional marriage system. Journal of Social Sciences and Public Affairs 4(1): 94-104.

Pesando, Luca Maria. 2021. Educational assortative mating in sub-Saharan Africa: Compositional changes and implications for household wealth inequality. Demography 58(2): 571-602.

Posel, Dorrit, and Stephanie Rudwick. 2013. Changing patterns of marriage and cohabitation in South Africa. Acta Juridica 2013(1): 169-180. 
Powers, Daniel A., Hirotoshi Yoshioka, and Myeong-Su Yun. 2011. mvdemp: Multivariate decomposition for nonlinear response models. The Stata Journal 11(4): 556-576.

Shapiro, David, and Tesfayi Gebreselassie. 2014. Marriage in sub-Saharan Africa: Trends, determinants, and consequences. Population Research and Policy Review 33(2): 229-255.

United Nations Population Division. 2003. World Fertility and Marriage Database. Available: http://data.un.org (accessed: 2 February 2010)

United Nations Population Division. 2019. World Population Prospects 2019. Available: https://population.un.org/wpp/DataQuery/

Westoff, Charles F. 1990. Age at marriage, age at first birth, and fertility in Africa. World Bank Publications

Westoff, Charles F. 2003. Trends in marriage and early childbearing in developing countries. DHS Comparative Reports No. 5. Calverton, Maryland: ORC Macro.

World Bank (2020). World Development Indicators. Available: https://databank.worldbank.org/source/world-development-indicators (Accessed: 27 May 2021)

Zuilkowski, Stephanie Simmons, Margaret Henning, Joseph Mumba Zulu, Beatrice Matafwali. 2019. "Once they fall pregnant, they don't come back": Teacher perspectives on Zambia's school re-entry policy for adolescent mothers. Teaching and Teacher Education 86: https://doi.org/10.1016/j.tate.2019.102880 